\title{
ANESTÉSICOS LOCAIS: INTERAÇÃO COM MEMBRANAS BIOLÓGICAS E COM O CANAL DE SÓDIO VOLTAGEM-DEPENDENTE
}

\section{Daniele Ribeiro de Araujo e Eneida de Paula}

Departamento de Bioquímica, Instituto de Biologia, Universidade Estadual de Campinas, CP 6109, 13083-970 Campinas - SP, Brasil

Leonardo Fernandes Fraceto*

Departamento de Engenharia Ambiental, Universidade Estadual Paulista Júlio de Mesquita Filho, Campus Sorocaba, Av. Três de Março, 511, 18087-180 Sorocaba - SP, Brasil

Recebido em 28/11/06; aceito em 30/11/07; publicado na web em 11/9/08

\begin{abstract}
LOCAL ANESTHETICS: INTERACTION WITH BIOLOGICAL MEMBRANES AND WITH THE VOLTAGE-GATED SODIUM CHANNEL. Many theories about the mechanism of action of local anesthetics (LA) are described in the literature. Two types of theories can be distinguished: those that focus on the direct effects of LA on their target protein in the axon membranes, i.e. the voltage-gated sodium channel and the ones that take into account the interaction of anesthetic molecules with the lipid membrane phase for the reversible nerve blockage. Since there is a direct correlation between LA hydrophobicity and potency, it is crucial to take this physico-chemical property into account to understand the mechanism of action of LA, be it on the sodium channel protein, lipid(s), or on the whole membrane phase.
\end{abstract}

Keywords: local anesthetic; membrane; voltage-gated sodium channel.

\section{INTRODUÇÃO}

Anestésicos locais (AL) compreendem um grande número de moléculas, de diferentes estruturas químicas, como amino-ésteres, amino-amidas, amino-cetonas, amidas, álcoois, tio-ésteres, tioamidas, derivados de uréia, poliéteres, ${ }^{1}$ derivados de monoterpenos do carano ${ }^{2}$ etc, capazes de bloquear reversivelmente a condução do estímulo nervoso.

As ações estimulatórias e euforizantes da cocaína, presente em grandes quantidades nas folhas de Erythroxylon coca, são conhecidas há séculos pelos povos andinos. Mas foi somente em 1860 que a cocaína foi isolada pela primeira vez por Albert Niemann, que constatou que a mesma causava entorpecimento da língua. As propriedades anestésicas da cocaína levaram à sua classificação como o primeiro anestésico de ação local. Em 1884, Carl Koller introduziu a cocaína na prática clínica como um anestésico para cirurgia oftalmológica ${ }^{3}$ e até o início do século XX era possível encontrar produtos cujo princípio ativo era a cocaína (Figura 1). Experiências posteriores, realizadas por Sigmund Freud e outros, demonstraram o grande potencial para desenvolvimento de dependência química, o que levou à proibição do uso da cocaína em 1914.

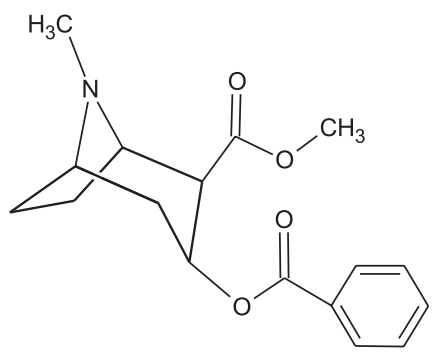

Figura 1. Estrutura química da cocaína

\footnotetext{
*e-mail: leonardo@sorocaba.unesp.br
}

Diferentes AL utilizados atualmente na clínica originam-se dessas primeiras observações clínicas. ${ }^{4,5}$ A tentativa de diminuir o potencial tóxico da cocaína levou ao desenvolvimento de análogos sintéticos e, em 1890, sintetizou-se a benzocaína, um éster derivado do ácido benzóico, assim como a cocaína. Mas foi em 1904 que apareceu o primeiro AL sintético com potencial uso infiltrativo, a procaína, que se tornou o protótipo dos AL durante quase meio século. ${ }^{6}$ Outros derivados do ácido para-amino benzóico, como a procaína, foram sintetizados depois e mostraram-se mais potentes (tetracaína) e menos tóxicos (clorprocaína) que a mesma (Tabela 1).

A toxicidade de metabólitos do ácido para-amino benzóico ${ }^{7}$ e a rápida metabolização da ligação éster por esterases plasmáticas limitavam o uso dos amino-ésteres, o que impulsionou a busca de novos compostos com atividade anestésica, levando à síntese dos AL tipo amino-amida, a partir de 1943 (Tabela 1), os quais atualmente são os agentes mais amplamente utilizados.

As amino-amidas são menos potentes que os amino-ésteres, porém seu grau de toxicidade sistêmica é relativamente menor, ${ }^{4}$ além de serem biotransformadas pelo fígado via citocromo $\mathrm{P} 450$, o que confere uma meia-vida plasmática mais longa em relação aos amino-ésteres. ${ }^{6,8}$

Analisando a Tabela 1 vê-se que a estrutura química típica dos anestésicos locais se caracteriza por uma região hidrofílica (normalmente um grupamento amina) e outra hidrofóbica (em geral um anel aromático) separadas por um grupo polar do tipo éster ou amida. Uma interessante exceção é a benzocaína, que não possui um grupamento amina ionizável e cujo bloqueio nervoso tem características especiais. ${ }^{9}$

Os anestésicos locais apresentam valores de pKa entre 7,6-8,9 (Tabela 2), o que pode gerar diferenças na proporção entre a forma neutra (maior partição em membranas ${ }^{10-13}$ ) e a carregada (que é responsável pela velocidade de ação ${ }^{4}$ ).

A Figura 2 mostra uma representação esquemática da ionização e da partição diferencial das formas protonada e neutra dos AL, na fase aquosa e membranar, conforme descrito na literatura. ${ }^{10-13}$ 
Tabela 1. Estrutura química dos anestésicos locais<smiles>[R]COC(=O)c1ccc(N[R])cc1[X]</smiles>

Estrutura 1

\begin{tabular}{lcccc}
\hline Anestésico local & $\mathrm{R}_{1}$ & $\mathrm{R}_{2}$ & Síntese & $\mathrm{pKa}$ \\
\hline Benzocaína & $-\mathrm{H}$ & $-\mathrm{CH}_{3}$ & 1890 & - \\
Procaína & $-\mathrm{H}$ & $-\mathrm{CH}_{2}-\mathrm{N}_{2}\left(\mathrm{C}_{2} \mathrm{H}_{5}\right)_{2}$ & 1905 & 8,9 \\
Tetracaína & $-\mathrm{C}_{4} \mathrm{H}_{9}$ & $-\mathrm{CH}_{2}-\mathrm{N}_{(}\left(\mathrm{CH}_{3}\right)_{2}$ & 1930 & 8,6 \\
\hline
\end{tabular}

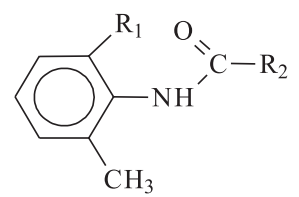

Estrutura 2

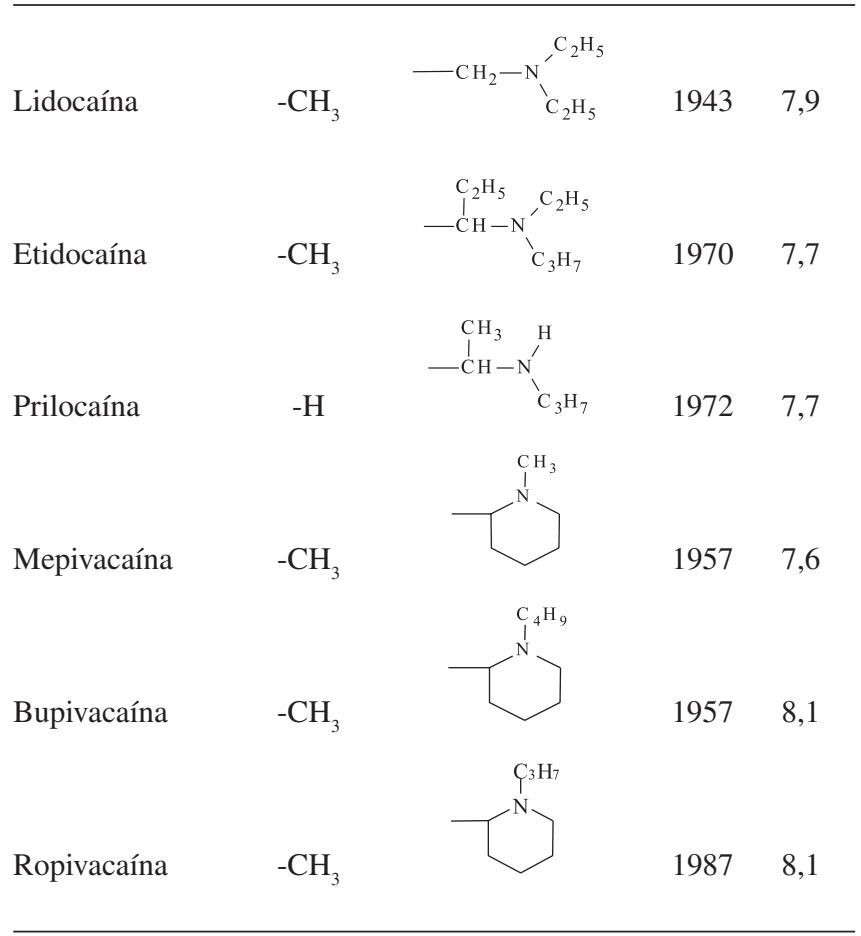

Tabela 2. Propriedades dos anestésicos locais

\begin{tabular}{lcccc}
\hline AL & Potência* & $\begin{array}{c}\text { Toxicidade } \\
\left(\mathrm{DL}_{50} \text { i.v. }\right) \\
\mathrm{mg} / \mathrm{kg}\end{array}$ & $\begin{array}{c}\text { Tempo de } \\
\text { anestesia } \\
(\mathrm{h})\end{array}$ & $\begin{array}{c}\text { Meia-vida } \\
\text { (h) }\end{array}$ \\
\hline Procaína & 1 & 367 & 1 & 0,1 \\
Clorprocaína & 4 & - & 0,75 & 0,1 \\
Tetracaína & 16 & 13 & 8 & 2,5 \\
Benzocaína & - & - & - & - \\
Lidocaína & 4 & 19,5 & 1,5 & 1,5 \\
Prilocaína & 3 & - & 1,5 & 1,5 \\
Etidocaína & 16 & 6,7 & 8 & 3,0 \\
Mepivacaína & 2 & 280 & 1,5 & 1,5 \\
Bupivacaína & 16 & 7,8 & 8 & 2,5 \\
Dibucaína & 16 & - & - & 11,0 \\
\hline
\end{tabular}

${ }^{*}$ Concentração para bloqueio, relativamente à da procaína.

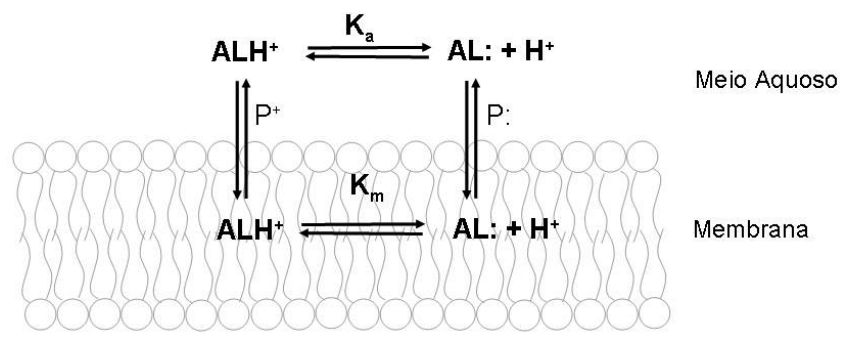

Meio Aquoso

Figura 2. Representação esquemática da partição/distribuição dos AL entre água e membrana, onde: $A L H^{+}$, molécula de $A L$ com grupamento amino protonado (forma ionizada); AL:, AL com grupamento amino desprotonado (forma neutra); $P$, coeficiente de partição; Ka, constante de dissociação em água; Km, constante de dissociação em membrana

Por serem moléculas anfifílicas, os AL têm grande afinidade pelas membranas celulares. Em membranas excitáveis, eles inativam canais de sódio voltagem-dependentes, impedindo o influxo de íons necessários à despolarização da membrana. ${ }^{4}$

As amino-amidas, como a lidocaína e a bupivacaína, e aminoésteres, como a tetracaína e benzocaína, são muito usados clinicamente. ${ }^{11}$ A importância clínica da lidocaína, uma amino-amida de caráter ionizável, e as propriedades particulares da benzocaína (citadas acima), um éster de baixa solubilidade e bastante empregado em anestesia tópica, nos levaram a escolher essas duas moléculas como modelos de estudo.

\section{HIPÓTESES PARA O MECANISMO DE AÇÃO DOS ANESTÉSICOS LOCAIS}

As teorias propostas para explicar os mecanismos de ação dos AL podem ser classificadas em duas categorias: a que atribui o efeito anestésico à ligação destes compostos à proteína canal de sódio e a que considera a interação dos AL com os componentes lipídicos da membrana (conhecida como "hipótese do lipídio") como determinante para o fechamento dos canais de sódio.

\section{Efeito direto dos AL no canal de sódio}

$\mathrm{Na}$ primeira categoria enquadram-se inúmeras tentativas de explicar a ligação direta dos AL em um ou mais sítios específicos do canal de sódio voltagem-dependente, alterando sua conformação e levando à inativação temporária do canal. ${ }^{12}$

Trabalhos na literatura mostram várias evidências da interação de AL com outras proteínas além do canal de sódio voltagem dependente, dentre elas, as sinalizadoras como: calmodulina, canais de potássio, receptores de acetilcolina, ATPases microssomais e mitocondriais, citocromo oxidase, proteína G, proteína EnvZ - que age na transdução de sinais por ativação da porina e proteína quinase $\mathrm{C} \alpha$, receptores de serotonina $1 \mathrm{~A}$, proteína tirosina kinase e receptores de opióides. ${ }^{13-18}$

Desde os trabalhos pioneiros de Hodgkin e Huxley, ${ }^{19}$ em 1953, sabe-se que os anestésicos locais têm efeito direto nos canais de sódio e que interagem com diferentes graus de afinidade com essas proteínas, dependendo de seu estado funcional (ativado, inativado, em repouso). Inicialmente postulou-se que essa afinidade diferencial estaria relacionada à presença das formas carregada e neutra dos anestésicos em $\mathrm{pH}$ fisiológico. Esta idéia foi bastante fortalecida quando, na década de 70, alguns pesquisadores verificaram que análogos quaternários de AL (sempre carregados) bloqueavam a condução nervosa somente quando aplicados internamente - na face citoplasmática - de axônios gigantes de lula perfundidos. Tais 
resultados foram interpretados como indicativos de que a forma carregada dos AL seria a responsável pelo efeito anestésico (ligação direta no canal) e que, como o sítio de ligação seria acessível apenas a partir da face interna da membrana, ${ }^{20,21}$ restaria à forma neutra dos AL (mais hidrofóbica) a função de facilitar a penetração dos anestésicos nas membranas.

No entanto, a boa potência anestésica de compostos como a benzocaína e seus análogos, que não se protonam em pH fisiológico, não encontrava apoio nesta descrição de sítio único para os $\mathrm{AL}$ protonados. ${ }^{22}$ Além disso, a grande variedade estrutural de moléculas com ação anestésica local levava a crer na existência de mais de um sítio receptor, ou de mais de uma via para o mecanismo de ação desses fármacos. ${ }^{12}$

O desenvolvimento quase simultâneo, na década de 80, de técnicas de mutação sítio-dirigida e patch-clamp permitiram estudar regiões específicas do canal (candidatas a sítios de ação dos AL) e também a eletrofisiologia de canais isolados, levando a um crescimento intenso nas pesquisas envolvendo proteínas canal. ${ }^{23}$

Em 1994, Catterall e colaboradores, usando técnicas de biologia molecular, conseguiram demonstrar a existência de um "sítio hidrofóbico" na proteína canal de sódio, para a forma neutra dos AL, situado no interior da bicamada, isto é, em uma $\alpha$-hélice transmembranar (S6, no domínio IV da subunidade $\alpha$ - Figura 3 ) da proteína canal de sódio voltagem-dependente de cérebro de ratos. Estes autores mostraram que a substituição de resíduos hidrofóbicos como a fenilalanina (1764) por alanina fazia decrescer, de 10 a 100 vezes, o bloqueio causado por AL nestes canais. ${ }^{24,25}$

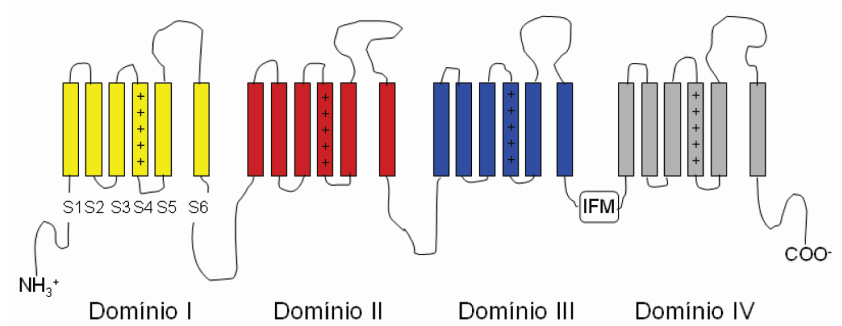

Figura 3. Representação da subunidade $\alpha$ do canal de sódio de cérebro de mamíferos e arranjo dos quatro domínios ao redor do poro central deste. Cada domínio apresenta seis hélices transmembranares (S1-S6)

Atualmente, a forma mais aceita de interpretar os inúmeros resultados envolvendo a interação entre anestésicos locais e proteína canal é dada pela hipótese da afinidade modulada pelo receptor (receptor-modulated) formulada por Hille, em 1977, que admite a existência de um ou mais sítios de ligação (receptor) para os AL no canal de sódio. As diferentes afinidades desses fármacos pelo(s) sítio(s) seriam moduladas pelo estado conformacional do canal, sendo maior a afinidade pelo estado inativo ou em repouso que pelo estado aberto. ${ }^{26,27}$

Em 1987, Starmer ${ }^{28}$ propôs, alternativamente, a hipótese do receptor guardado ou protegido (guarded receptor), que assume que os rearranjos conformacionais do canal de sódio que acompanham a despolarização permitem o acesso da molécula do anestésico ao seu sítio receptor, cuja afinidade seria sempre constante. Esta proposta, não tão conhecida ou aceita quanto a de Hille, tem a vantagem de conceber interações entre o AL e outros estados conformacionais do canal, que não somente o inativado. Assim, os AL poderiam agir como efetor alostérico que, ao interagir em seu(s) sítio(s) específico(s) estabilizariam o canal no estado inativado, já que os quatro domínios da subunidade alfa estão envolvidos na inativação lenta produzida pelos AL. ${ }^{29}$

\section{Interações não específicas entre anestésicos locais e membranas}

Na "hipótese do lipídio" considera-se que as alterações causadas pelos anestésicos nas propriedades estruturais e dinâmicas da matriz lipídica levariam a mudanças conformacionais no canal de sódio, explicando sua inativação. ${ }^{30}$

Estudos clássicos da literatura mostram que os AL agem sobre sistemas membranares, alterando-os de diversas maneiras. Analisando apenas a fase lipídica membranar, foram observados efeitos de expansão da bicamada e diminuição na temperatura de transição de fase principal, o que aumentaria a fluidez e a permeabilidade da membrana. ${ }^{13}$

A incorporação de AL pela fase lipídica causa uma expansão da área superficial de monocamadas ${ }^{31}$ e bicamadas; ${ }^{32,33}$ esta expansão seria favorecida pela diferença entre o comprimento da molécula do AL (mais curto) e dos fosfolipídios. Assim, abaixo do seu ponto de inserção o anestésico criaria um "volume livre", que seria compensado com uma mudança conformacional das cadeias acilas dos lipídios adjacentes, causando diminuição no comprimento total da bicamada e expansão lateral da mesma. ${ }^{34,35}$

De fato, Hill ${ }^{36}$ observou uma diminuição da espessura da bicamada, seguindo alterações da temperatura de transição de fase causadas por anestésicos gerais, locais e álcoois.

Diminuições na temperatura de transição de fase foram observadas por diferentes grupos de pesquisadores utilizando várias técnicas. Lee, ${ }^{37,38}$ empregando calorimetria, registrou diminuição da temperatura de transição de fase de vesículas, constituídas pelo lipídio dipalmitoil fosfatidilcolina, causada pela partição dos AL benzocaína, procaína, tetracaína, lidocaína e dibucaína, em concentrações iguais às necessárias para $50 \%$ de bloqueio na condução do estímulo nervoso. Esses achados foram depois descritos também para a forma neutra da procaína, tetracaína, lidocaína e bupivacaína, pela técnica de espalhamento de luz. ${ }^{39}$

$\mathrm{O}$ efeito dos AL no empacotamento dos fosfolipídios em membranas modelo e biológicas foi bastante estudado por ressonância paramagnética eletrônica (RPE) e outras técnicas espectroscópicas, como ressonância magnética nuclear (RMN), infravermelho e fluorescência. $^{13}$

Através da técnica de absorção no infravermelho, demonstrouse a incorporação da dibucaína e procaína em monocamadas de palmitoiloleil fosfatidilcolina, estudando as bandas de absorção dos compostos, entre 1400 e $1800 \mathrm{~cm}^{-1} \cdot{ }^{40}$ A combinação de estudos de infravermelho com variação de pressão possibilitou a Auger e colaboradores demonstrarem que a tetracaína, incorporada em membranas sintéticas (dimiristoilfosfatidilcolina, dioleilfosfatidilserina e dipalmitoilfosfatidilcolina) e biológicas, é expulsa da bicamada por aumento da pressão. ${ }^{41,42}$ Esse achado veio explicar observações anteriores, in vivo, de reversão do efeito de anestésicos com aumento de pressão ${ }^{43}$ e explicar porque os AL penetram menos em membranas biológicas, com a diminuição da temperatura. ${ }^{44}$

Ainda utilizando infravermelho, um estudo mostrou a diferente inserção de dois anestésicos locais (lidocaína e benzocaína) em vesículas unilamelares de fosfatidilcolina de ovo. ${ }^{45}$ Neste estudo, a lidocaína (na forma neutra) e a benzocaína inserem-se próximas à região do glicerol, enquanto que a lidocaína carregada se localiza próxima ao grupamento fosfato/colina dos fosfolipídios.

Medidas de fluorescência revelaram importantes informações sobre a localização de AL em vesículas fosfolipídicas. Estudos utilizando o AL tetracaína como supressor de fluorescência de marcadores fluorescentes incorporados em diferentes profundidades no interior da bicamada indicaram uma inserção da forma neutra do anestésico nas regiões menos polares, além de detectar diferentes mobilidades locais nas cadeias acilas dos fosfolipídios..$^{46,47}$ 
Medidas de ressonância paramagnética eletrônica (RPE) foram realizadas com AL modificados, isto é, covalentemente ligados a radicais nitróxido ${ }^{48,49}$ e também empregando radicais nitróxido ligados a ácidos graxos ou seus derivados. ${ }^{35,50-54}$ Esses estudos mostraram que a incorporação dos AL na bicamada lipídica é acompanhada por uma diminuição de ordem e aumento na dinâmica membranar. Em um estudo sistemático envolvendo AL das séries amino-amida e amino-éster ${ }^{53}$ foi observado que o efeito de diminuição da organização de membranas lipídicas não está relacionado diretamente à hidrofobicidade ou classe dos AL. Esses resultados foram reforçados por outro estudo realizado em nosso laboratório, que correlacionou resultados de ressonância magnética nuclear (RMN) e RPE na análise da interação de AL com membranas multilamelares ${ }^{22}$ (grandes) e unilamelares (pequenas) de fosfatidilcolina de ovo. ${ }^{22,54}$ Foram encontradas evidências de que parâmetros estéricos dos AL determinariam sua localização preferencial no interior da bicamada.

Os primeiros experimentos empregando RMN de hidrogênio detectaram imobilização da molécula do AL quando intercalado na bicamada lipídica, ${ }^{55-59}$ isto é, um efeito semelhante ao observado por RPE com análogos paramagnéticos dos AL. ${ }^{48,49}$

Com experimentos de RMN de deutério, ${ }^{2} \mathrm{H}-\mathrm{RMN}$, e a utilização de AL e lipídios seletivamente deuterados foi possível, pela primeira vez, identificar as regiões da membrana lipídica nas quais se inseriam preferencialmente os AL. ${ }^{60-65} \mathrm{O}$ trabalho de Boulanger e colaboradores $^{60}$ tornou-se citação obrigatória na área, sendo citado até os dias de hoje por ter demonstrado, inequivocamente, a localização diferencial das formas protonada (mais superficial) e neutra da tetracaína em vesículas de fosfatidilcolina de ovo. Resultados semelhantes foram encontrados com o anestésico local dibucaína por ${ }^{2} \mathrm{H}-\mathrm{RMN}$ onde se observou uma localização próxima aos primeiros carbonos do glicerol. ${ }^{66}$

Medidas de ${ }^{1} \mathrm{H}-\mathrm{RMN}$ foram favorecidas com o desenvolvimento de espectrômetros de RMN de alta resolução e de novas técnicas, que possibilitaram a obtenção de informações sobre a localização dos AL. Trabalhos na literatura relatam sobre a perturbação da bicamada provocada pela inserção de tetracaína, procaína e dibucaína, bem como a sua localização no interior das bicamadas, ${ }^{67-69}$ sendo estes de acordo com os achados de estudos utilizando ${ }^{2} \mathrm{H}-\mathrm{RMN}$.

No entanto, poucos relatos na literatura tratam da forma neutra dos AL, 9, 13,22,46,53,54,60-62,64,70,71 a despeito da maior interação desta com a fase lipídica da membrana e das evidências de que o pK aparente de diferentes $\mathrm{AL}^{10,37,38,50}$ diminui significativamente na presença de membranas com interfaces zwitteriônicas, com o conseqüente efeito sobre a proporção da forma catiônica e da forma neutra do AL.

Acredita-se que a dificuldade imposta pela baixa solubilidade aquosa dos AL desprotonados, além da falsa idéia introduzida a partir dos trabalhos de Narahashi e Frazier ${ }^{20,21}$ de que a forma protonada dos AL seria a responsável pelo mecanismo de ação dos AL, tenha limitado seu estudo até aqui. A importância da forma neutra dos AL só foi retomada na década de 90, depois que os trabalhos de Ragsdale e colaboradore ${ }^{24,25}$ mostraram interação entre anestésicos não carregados e a proteína canal de sódio.

\section{ESTRUTURA DO CANAL DE SÓDIO VOLTAGEM- DEPENDENTE}

O canal de sódio (Figura 3) é uma glicoproteína de membrana que se encontra principalmente em axônios e músculo e é ativada pela despolarização da membrana - abrindo seu poro central e permitindo a entrada de sódio, o que leva à propagação do estímulo nervoso; é seletiva ao íon sódio (a passagem de $\mathrm{K}^{+}$equivale a cerca de $8 \%$ da de $\mathrm{Na}^{+}$). Estudos indicam que os canais de sódio voltagemdependentes são compostos por uma subunidade $\alpha$ (formadora do poro do canal) podendo estar associada a quatro diferentes tipos de subunidades $\beta .^{72-74}$

No caso de canais de sódio de cérebro de rato, experimentos usando anticorpos anti-peptídeos das subunidades $\beta 1$ e $\beta 2$ mostraram que a maior parte destes têm ambas subunidades $\beta{ }^{73,74}$

A subunidade $\alpha$ tem $260 \mathrm{kDa}$ e quatro domínios homólogos (IIV), cada qual contendo 6 hélices transmembranares; ${ }^{73,74}$ as subunidades $\beta$ têm 23 e $21 \mathrm{kDa}$ cada, sendo que $\beta 2$ está ligada à subunidade por pontes dissulfeto, enquanto $\beta 1$ liga-se não covalentemente a $\alpha .^{23}$ Cada subunidade $\beta$ tem um grande segmento amino terminal extracelular, com várias regiões de consenso para $\mathrm{N}$-glicosilação. Canais de músculo esquelético têm a subunidade $\alpha(260 \mathrm{kDa})$ e uma ou duas subunidades $\beta$ (com $38 \mathrm{kDa}$ cada), enquanto os canais voltagemdependente de enguia e de coração de galinha apresentam apenas a subunidade $\alpha .{ }^{72}$ Canais de sódio pertencem à mesma família dos canais de potássio e de cálcio voltagem-dependentes, com os quais sua arquitetura molecular guarda várias similaridades. ${ }^{74}$

O canal de sódio é o mais estudado dos canais voltagemdependentes. A presença dessa proteína determina a especialização funcional de muitos tipos de células, como neurônios sensoriais e células cardíacas, principalmente em processos fisiológicos, como dor, inflamação e contratilidade. A via mais eficaz para correlacionar a expressão de canais de sódio voltagem-dependentes com as características biofísicas de células excitáveis é determinar propriedades como velocidade de condução do potencial de ação e influxo de sódio, o que tem auxiliado cada vez mais no entendimento de seu mecanismo de ação, bem como de agentes que agem sobre o canal como anestésicos locais e toxinas. ${ }^{75}$

Em 1952, Hodgkin e Huxley demonstraram que os fenômenos de abertura (gating) e permeação de íons estavam relacionados com mais de dois estados funcionais: aberto, fechado e inativado. ${ }^{19}$ Essa proteína foi também o primeiro canal desse tipo a ser clonado ${ }^{23}$ e seu estudo beneficiou-se ainda do desenvolvimento, na mesma época, da técnica de patch-clamp, que permite a medida do potencial elétrico de canais isolados. ${ }^{76}$

A característica dessa família de canais voltagem-dependentes é a presença de quatro domínios transmembranares homólogos (canais de sódio e cálcio) ou quatro subunidades homólogas (canais de potássio), onde cada domínio ou subunidade apresenta seis segmentos em $\alpha$-hélice, S1 a S6, como mostrado na Figura 3. ${ }^{72,74,77}$ Os domínios ou subunidades organizam-se de forma a apresentar um poro central seletivo ao sódio. Segundo Marban e colaboradores, ${ }^{74}$ os canais de sódio devem ter surgido a partir da mutação de canais de cálcio que, por sua vez, evoluíram por duplicação da informação gênica dos canais de potássio.

Em cada domínio ou subunidade a $\alpha$-hélice $S 4$ - contendo vários resíduos de aminoácidos carregados positivamente - tem importância fundamental no processo de abertura do poro em ambos os canais. Como esses canais voltagem-dependentes não possuem uma molécula ativadora específica, as $\alpha$-hélices $\mathrm{S} 4$ formam a região sensora ou de disparo do canal (voltage-sensing ou gating sensor). ${ }^{77}$ A mudança do potencial da membrana desestabiliza o segmento $\mathrm{S} 4$, cujas cargas positivas são mantidas por pareamento com cargas negativas de outros segmentos transmembranares. Com a despolarização da membrana reduzem-se as forças que mantêm as cargas positivas de S4 na sua posição e a hélice inteira sofre uma rotação (movimento espiral de cerca de $60^{\circ}$, projetando-se em $5 \AA$ para fora da bicamada, do lado extracelular). Esse movimento deixa uma carga negativa não pareada no interior da bicamada e expõe uma carga positiva na superfície externa da membrana, resultando na transferência de carga líquida de $+1 .^{72}$

Outra similaridade entre os canais é o filtro de seletividade, formado pelas alças extracelulares S5-S6 (denominadas segmentos 
P) dos domínios I a IV. Essa é uma região bastante conservada entre os canais de $\mathrm{Na}^{+}, \mathrm{K}^{+}$e $\mathrm{Ca}^{+2}$ e é considerada o filtro do canal, pois as alças se dobram sobre o poro, como demonstrado com resolução de 3,2 A por cristalografia de Raios-X dos canais de $\mathrm{K}^{+} .{ }^{78}$

Nos canais de sódio, outra região extremamente importante é o sítio de inativação (inactivating gate), formado pela alça intramembranar entre os domínios III (S6) e IV (S1), que se projeta (como tampa ou portão) sobre o lúmem interno do poro, inativando-o. ${ }^{77,79}$ Anticorpos preparados contra esse segmento são capazes de inibir completamente a inativação do canal. ${ }^{79}$ Estudos de mutação sítio-específica mostraram que os resíduos isoleucina-fenilalanina-metionina (IFM, nas posições 1488, 1489, 1490 do canal de sódio de cérebro humano), ali situados, são fundamentais para a inativação espontânea do canal e formariam o "trinco do portão", mantendo-o fechado sobre o poro, ${ }^{77,79}$ como ilustrado na Figura 4. Já os segmentos S5 e S6 de cada um dos domínios do canal de sódio são organizados na proteína de forma a constituir a parte interior do poro do canal. ${ }^{80,81}$
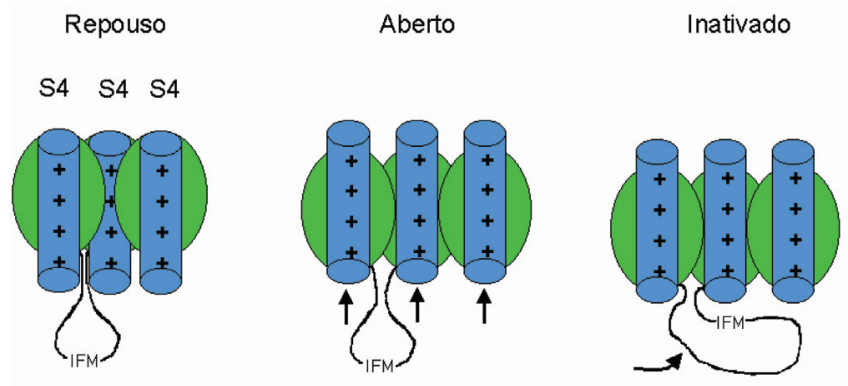

Figura 4. Modelo para ativação e inativação do canal de sódio voltagem dependente

Sítios de regulação - por fosforilação - pela proteína quinase dependente de AMPc foram encontrados na isoforma neuronal e em várias isoformas cardíacas do canal, especificamente na alça intracelular entre os domínios I e II $7^{74}$ a fosforilação diminui a amplitude da corrente e altera a condutância total da célula. A proteína quinase $\mathrm{C}$ também altera o funcionamento de todas as isoformas dos canais de sódio de mamíferos. O sítio de fosforilação é uma serina, altamente conservada, na alça entre os domínios III e IV; a fosforilação pela proteína quinase $\mathrm{C}$ reduz a condutância máxima do canal e altera sua ativação. ${ }^{72-74,82-88}$

A Tabela 3 resume as informações acima, apresentando regiões específicas relacionadas a diferentes funções ou à regulação do canal de sódio voltagem-dependente.

\section{COMPOSTOS QUE INTERAGEM ESPECIFICAMENTE COM O CANAL DE SÓDIO E MODIFICAM SEU FUNCIONAMENTO}

Moléculas que interagem especificamente com o canal de sódio incluem toxinas, anestésicos locais e anticonvulsivantes (carbamazepina, fenitoína, ácido valpróico, entre outros). ${ }^{86}$

Várias toxinas são capazes de impedir a condução do estímulo nervoso ao se ligarem fortemente e especificamente ao canal de sódio voltagem-dependente. Estudos farmacológicos com canais de sódio indicam que neurotoxinas agem em sítios distintos no canal de sódio e apresentam como efeitos primários alterações na permeação iônica (poro do canal) e na região sensora de canais de sódio voltagemdependente. ${ }^{81}$ Estes sitios de ação foram encontrados por estarem alostericamente acoplados, sugerindo que mudanças conformacionais induzidas pela ligação de neurotoxinas alteram o equlíbrio entre os estado aberto e os estados fechado/inativado.$^{81} \mathrm{Um}$ resumo das in-
Tabela 3. Regiões estudadas do canal de sódio e suas respectivas funções, de acordo com trabalhos de mutação sítio específica e eletrofisiologia

\begin{tabular}{lll}
\hline Região & Função & Refs. \\
\hline Hélice S4 & Região sensora (gating & $72-74,82,83$, \\
(Domínio IV) & $\begin{array}{l}\text { sensor) responsável pela } \\
\text { ativação do canal }\end{array}$ & 86,87
\end{tabular}

Alças S5-S6

Filtro de seletividade

$72-74,83-85$

(Domínios I-IV)

iônica, composto pelo

dobramento das alças

(segmentos $\mathrm{P}$ )

Alça S6-S1

Partícula de inativação

$72-74,82-88$

(Domínios III-IV)

(inactivating gate particle)

ou tampa interna do canal;

inclui também o sítio de

fosforilação por proteína

quinase $\mathrm{C}$

Hélice S5 e S6

Formam o poro do canal

$72-74,82-88$

(Domínios I-IV)

Alça S6-S1
(Domínio I e II)

Sítios de fosforilação

pela proteína quinase

dependente de AMPc

Alças S3-S4 e

Sítios de glicosilação

S5-S6 (Domínio

I), Alças S1-S2

e S5-S6 (Domínio

II) e alça S5-S6

(Domínio III)

terações das toxinas com canais de sódio voltagem-depentente está apresentado na Tabela $4 .{ }^{81}$

Já para o entendimento do mecanismo de ação dos anestésicos locais, postulou-se inicialmente que estes compostos poderiam agir de forma semelhante a bloqueadores de origem natural (neurotoxinas), ou seja, na parte extracelular do canal. Porém, já nos anos 70, Narahashi e colaboradores mostraram que anestésicos locais carregados causavam bloqueio de canais de sódio quando infiltrados pelo lado citoplasmático da membrana de axônios de lagosta. ${ }^{20,21}$

Embora aminas ionizáveis representem a grande maioria das moléculas com atividade anestésica, há exceções importantes (como o éster benzocaína) e o entendimento de que tanto as formas neutra quanto a protonada dos AL devem ser consideradas na sua ação sobre o canal de sódio é uma premissa recente. Os achados de Narahashi e colaboradores ${ }^{20,21}$ desviaram a atenção dos pesquisadores da importância de ambas as formas dos AL, embora não explicassem como a benzocaína, uma molécula neutra em $\mathrm{pH}$ fisiológico, produz bloqueio tônico e dose-independente durante repetidas despolarizações. ${ }^{22}$

Ao longo dos anos, vários trabalhos relevantes apareceram na literatura tentando descrever os mecanismos moleculares envolvidos com o efeito farmacológico dos AL. ${ }^{24,25,80,88-91}$ As primeiras descrições da interação AL-canal de sódio só apareceram na década de 90, através de técnicas de mutação sítio-específica. Ragsdale e colaboradore $^{24,25}$ demonstraram a existência de um "sítio hidrofóbico" para o anestésico local Etidocaína no interior da $\alpha$-hélice S6 do domínio IV da subunidade $\alpha$ da proteína canal de sódio de cérebro. ${ }^{91}$ Segundo Ragsdale e colaboradores a $\alpha$-hélice S6 (domínio IV), próxima ao lúmen interno do canal, constituiria o sítio de ação dos anestésicos 
Tabela 4. Sítios de ação identificados para neurotoxinas nos canais de sódio voltagem dependentes

\begin{tabular}{|c|c|c|c|}
\hline & Toxina & Domínio & Aminoácido \\
\hline \multirow[t]{8}{*}{ Sítio 1} & Tetrodotoxina & I (S5-S6) & $\mathrm{D}^{384}, \mathrm{E}^{387}, \mathrm{Y}^{385}$ \\
\hline & Saxitoxina & II (S5-S6) & $\mathrm{E}^{942}, \mathrm{E}^{945}$ \\
\hline & & III (S5-S6) & $\mathrm{K}^{1422}, \mathrm{D}^{1426}$ \\
\hline & & IV (S5-S6) & $\mathrm{D}^{1426}$ \\
\hline & $\mu$-conotoxina & I (S5-S6) & $\begin{array}{c}\mathrm{D}^{400}, \mathrm{Y}^{401}, \mathrm{~W}^{402}, \\
\mathrm{E}^{403}\end{array}$ \\
\hline & & II (S5-S6) & $A^{728}, A^{730}, E^{758}$ \\
\hline & & III (S5-S6) & $\mathrm{W}^{1239}, \mathrm{D}^{1241}$ \\
\hline & & IV (S5-S6) & $\mathrm{W}^{1531}, \mathrm{D}^{1532}$ \\
\hline \multirow[t]{3}{*}{ Sítio 2} & Veratridina & I (S6) & $\mathrm{I}^{433}, \mathrm{~N}^{434}, \mathrm{~L}^{437}$ \\
\hline & Batrachotoxina & & \\
\hline & Grayanotoxina & IV (S6) & $\begin{array}{c}\mathrm{F}^{1579}, \mathrm{~N}^{1584}, \mathrm{Y}^{1586}, \\
\mathrm{I}^{1760}, \mathrm{I}^{1764}\end{array}$ \\
\hline \multirow[t]{3}{*}{ Sítio 3} & $\begin{array}{l}\text { Toxinas } \alpha \text { de } \\
\text { escorpião }\end{array}$ & I (S5-S6) & \\
\hline & $\begin{array}{l}\text { Toxinas de anê- } \\
\text { mona do mar }\end{array}$ & IV (S5-S6) & $E^{1613}$ \\
\hline & Toxinas de aranhas & IV (S3-S4) & $\mathrm{E}^{1616}, \mathrm{~V}^{1620}, \mathrm{~L}^{1624}$ \\
\hline \multirow[t]{4}{*}{ Sítio 4} & \multirow{4}{*}{$\begin{array}{c}\text { Toxinas } \beta \text { de es- } \\
\text { copião }\end{array}$} & I (S5-S6) & \\
\hline & & II (S1-S2) & $G^{845}$ \\
\hline & & II (S3-S4) & \\
\hline & & III (S5-S6) & \\
\hline Sítio 5 & Brevetoxina & I (S6) & $?$ \\
\hline \multirow[t]{2}{*}{ Sítio 6} & Ciguatoxina & IV (S5) & \\
\hline & $\delta$-conotoxinas & $?$ & $?$ \\
\hline \multirow{3}{*}{$\begin{array}{l}\text { Sítio para } \\
\text { toxina } \\
\text { excitatória }\end{array}$} & \multirow{3}{*}{$\begin{array}{l}\text { Toxinas excitatórias } \\
\text { de escorpião }\end{array}$} & I (S5-S6) & \\
\hline & & III (S5-S6) & \\
\hline & & IV (S5-S6) & $?$ \\
\hline \multirow{3}{*}{$\begin{array}{l}\text { Sítio para } \\
\text { toxina } \\
\text { depressora }\end{array}$} & \multirow{3}{*}{$\begin{array}{l}\text { Toxinas depressoras } \\
\text { de escorpião }\end{array}$} & I (S5-S6) & \\
\hline & & III (S5-S6) & \\
\hline & & IV (S5-S6) & $?$ \\
\hline
\end{tabular}

locais com dois resíduos aromáticos de aminoácidos, $\mathrm{F}^{1764}$ (situada no meio da $\alpha$-hélice transmembranar, correspondente à região de estreitamento do canal de $\mathrm{K}^{+}$revelada pelos estudos de Raios- $\mathrm{X}^{78}$ ) e $\mathrm{Y}^{1771}$ (próxima à face interna da membrana) seriam fundamentais para a interação com o AL. ${ }^{24} \mathrm{O}$ possível modo de interação (hidrofóbico, cátion-elétron $\pi$ ou aromático-aromático) foi demonstrado posteriormente ser a interação dependente do estado do canal, ${ }^{92}$ indicando que o sítio de ação é uma estrutura dinâmica. Além dessa região, os resíduos de aminoácidos $\mathrm{L}^{1465}, \mathrm{~N}^{1466}, \mathrm{I}^{1469}$ na hélice $\mathrm{S} 6$ do domínio III e o resíduo de I ${ }^{409}$ na hélice S6 do domínio I parecem fazer parte do sítio de ligação dos anestésicos locais. ${ }^{80}$

Um estudo utilizando mutações de aminoácidos do canal de sódio de músculo esquelético de rato por cisteína encontrou que vários aminoácidos podem determinar a ligação da lidocaína, dentre eles: ${ }^{424}$, $\mathrm{I}^{425}$ e $\mathrm{G}^{428}$ na hélice S6 do domínio I e $\mathrm{I}^{782}$ e V $^{786}$ da hélice S6 do domínio II, baseado na observação de que as mutações por cisteína destes resíduos alteram a sensibilidade do canal quando em presença de lidocaína. ${ }^{93}$
Desta forma, são fortes as evidências de que o sítio de ligação dos AL envolve múltiplos segmentos S6 dos domínios do canal de sódio voltagem-dependente. Este fato implica que os segmentos S6 estariam próximos no espaço, contribuindo assim para a interação com uma molécula pequena como a dos anestésicos locais ${ }^{88}$ No entanto, estes pontos de contato não são estáticos e podem depender de ambos, do estado do canal e do tipo de anestésico local testado.

Por outro lado, se a ligação do anestésico ocorresse somente nas hélices S6, isto é, alterasse diretamente estruturas relacionadas ao poro do canal, não seria possível justificar que modificações na partícula de inativação alterassem a ação do anestésico local, como demonstrado por Bennett e colaboradores. ${ }^{94}$

Kuroda e colaboradores, empregando ${ }^{1} \mathrm{H}-\mathrm{RMN}$, encontraram resultados que indicariam a interação dos AL com a partícula de inativação, isto é, a alça entre o domínio III ( $\alpha$-hélice S6) e IV ( $\alpha$-hélice S1) que mantém o canal fechado durante o período refratário (período em que um novo potencial de ação não pode ocorrer em uma fibra excitável devido ao fato de a membrana estar despolarizada pelo potencial de ação anterior) e período de repouso (período quando não se tem sinais nervosos transmitidos, tendo um valor de potencial de membrana de cerca de $-90 \mathrm{mV}$ ). Segundo esses autores, a presença do anestésico nesta região prolonga o estado inativado do canal de sódio, tornando impossível a transmissão do impulso nervoso. ${ }^{66}$

Concomitantemente, estudos de mutações sítio-específicas ${ }^{95-100}$ revelaram que a alça que liga as $\alpha$-hélices S4 e S5 do domínio IV seria também importante para o processo de inativação do canal. ${ }^{77,97}$, ${ }_{99,100}$ A pequena alça intracelular que conecta os segmentos S4 e S5, tanto no domínio III ${ }^{99}$ quanto no domínio IV, ${ }^{77,98}$ tem sido sugerida como boa candidata a este papel regulador. McPhee e colaboradores mostraram que os resíduos $\mathrm{F}^{1651}, \mathrm{~L}^{1660}$ e $\mathrm{N}^{1662}$ da alça S4-S5 do domínio IV estabelecem interações com os resíduos IFM da partícula de inativação do canal de sódio, tanto inativado quanto fechado. ${ }^{97}$ Estudos de mutação sítio-específica mostraram que a substituição de resíduos hidrofóbicos anteriores a $\mathrm{P}^{1473}$ da alça S4-S5 do domínio IV levaram a canais não funcionais, indicando que esta alça intracelular tem um papel importante na inativação de canais de sódio de músculo esquelético de rato ${ }^{99,100}$ e de músculo cardíaco humano. ${ }^{98}$ Yang e colaboradores ${ }^{101,102}$ demonstraram a existência de interações espaciais entre resíduos não polares desta alça citoplasmática e resíduos do canal, em resposta à despolarização, resultados que levaram Filatov e colaboradores ${ }^{100}$ a sugerir que estas interações facilitariam a formação de um sítio de existência transitória, para ligação da partícula de inativação, estabilizando o canal no estado inativado.

Como os determinantes estruturais da inativação rápida do canal são os resíduos hidrofóbicos (IFM) da partícula de inativação, a existência de um receptor para a partícula de inativação poderia explicar a estabilização do canal no estado não-condutor. Este receptor seria formado pelos resíduos da parte final (intracelular) da hélice S6 do domínio IV e também pelas alças S4-S5 dos domínios III e IV, segundo recente revisão de Nau e Wang ${ }^{88}$ o que cria a hipótese de um outro possível sítio de ação dos anestésicos locais, uma vez que os anestésicos têm uma interação preferencial com a forma inativa do canal de sódio. ${ }^{26} \mathrm{~A}$ ligação do anestésico a este receptor estabilizaria a interação receptor-partícula, e poderia ser a responsável pelo mecanismo de inativação dos canais induzido por AL.

Nosso grupo recentemente apresentou a hipótese de que a alça citoplasmática S4-S5 do domínio IV (que faz parte da partícula de inativação) seja um sítio de ação de lidocaína e benzocaína. ${ }^{9}$ A estrutura tridimensional desta alça citoplasmática S4-S5 do domínio IV foi determinada por ${ }^{1} \mathrm{H}-\mathrm{RMN}$ em micelas de dodecilsulfato de sódio ${ }^{103} \mathrm{e}$ em trifluoretanol. ${ }^{9}$ A interação com dois anestésicos locais (lidocaína e benzocaína) foi estudada por ${ }^{1} \mathrm{H}-\mathrm{RMN},{ }^{9}$ indicando que a interação se dá com resíduos hidrofóbicos da alça. Esta região é importante 
Tabela 5. Regiões de interação entre anestésicos locais e canal de sódio voltagem-dependente

\begin{tabular}{lcc}
\hline Região & \multicolumn{1}{c}{ Importância } & Refs. \\
\hline Hélice S6 & Maiores evidências de sítio de & $24,25,80$, \\
(Domínios I a IV) & $\begin{array}{c}\text { ligação de anestésicos locais } \\
\text { Região da partícula de }\end{array}$ & 88,93 \\
$\begin{array}{l}\text { Alça S6-S1 } \\
\text { (Domínios III-IV) }\end{array}$ & $\begin{array}{c}\text { inativação - Motivo IFM } \\
\text { Hélice S6 } \\
\text { (Domínio IV) }\end{array}$ & $\begin{array}{c}\text { Parte do receptor da partícula } \\
\text { de inativação e sítio de ligação } \\
\text { de anestésicos locais }\end{array}$ \\
$\begin{array}{l}\text { Alça S4-S5 } \\
\text { (Domínio IV) }\end{array}$ & $\begin{array}{c}\text { Partes do receptor da partícula } \\
\text { de inativação, relacionada }\end{array}$ & 91,88 \\
$\begin{array}{l}\text { Alça S4-S5 } \\
\text { (Domínio III) }\end{array}$ & com a inativação do canal \\
\hline
\end{tabular}

para o mecanismo de ação dos anestésicos locais, pois estabiliza o fechamento do canal pela partícula de inativação, favorecendo o estado inativado do canal de sódio voltagem-dependente.

Um trabalho recente, de dinâmica molecular in silico, mostrou o docking do AL benzocaína na hélice S6 do domínio IV. ${ }^{71}$ Neste trabalho os autores, embora tenham focado somente em resíduos na região da hélice S6 do domínio IV, reconheceram que este pode ser um possível sítio de ação da benzocaína. No entanto, descrevem que uma melhor investigação em outras regiões do canal deva ser realizada. ${ }^{71}$

A Tabela 5 resume as regiões descritas na literatura como possíveis sítios de ação dos anestésicos locais em canais de sódio voltagem-dependentes.

\section{CONCLUSÕES}

Os mecanismos de ação dos AL propostos na literatura envolvem tanto a interação com a fase lipídica membranar quanto com sítio(s) na proteína canal de sódio voltagem-dependente, como representado esquematicamente na Figura 5.

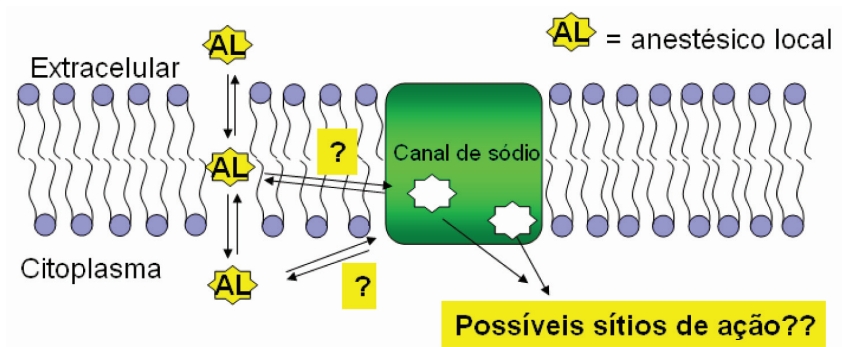

Figura 5. Esquema ilustrativo da interação de anestésicos locais com a fase lipídica e as possíveis vias de acesso destes a(os) sítio(s) de ação na proteína canal de sódio

Propõe-se atualmente que os AL se ligam a uma ou mais regiões diferentes da proteína canal de sódio, bloqueando o transporte desses íons. ${ }^{24,25,86}$ Por outro lado, a correlação direta entre hidrofobicidade e potência anestésica revela que a partição/distribuição inespecífica de grande quantidade do AL na bicamada lipídica é importante para facilitar o acesso da molécula ao(s) sítio(s) de ligação no canal de sódio voltagem-dependente. ${ }^{13}$

A teoria dos lipídios sugere que o AL, por sua atividade na bicamada lipídica, produza uma alteração no empacotamento dos lipídios, causando uma modificação conformacional nos canais de sódio, o que levaria à inativação temporária do mesmo. Também é interessante notar que essa teoria prevê a ligação inespecífica de grande quantidade de AL na fase lipídica, para que haja a alteração significante da fluidez e permeabilidade da membrana. ${ }^{104}$ É a lipofilicidade dos AL que permite a concentração de grandes quantidades do composto nas membranas, o que facilitaria seu acesso aos sítios de ação na proteínacanal e determinaria a potência do bloqueio nervoso. ${ }^{13}$

Sabe-se ainda que a interação específica dos AL com os canais de sódio é dependente do estado conformacional destes, ocorrendo preferencialmente quando do estado inativado, provocando desta forma a não condução de íons. Quanto maior o número de canais na forma inativada, mais fácil é a instalação do bloqueio, tal que o aumento na freqüência de estimulação de uma fibra possibilita que mais canais se abram, se fechem e se inativem, aumentando a afinidade pelos AL. Este fenômeno é denominado bloqueio dependente de freqüência ou bloqueio uso-dependente. ${ }^{105}$

De acordo com as idéias do clássico trabalho de Hille, ${ }^{26}$ outras regiões dos canais devem ser consideradas como potenciais sítios de ação para os AL. Essas regiões incluiriam os resíduos hidrofóbicos da alça entre os domínios III e IV da partícula de inativação, ${ }^{24}$ resíduos próximos à prolina da alça S5-S6 dos domínios I e IV, envolvidos com o controle da seletividade específica dos canais, ${ }^{106}$ bem como a alça intracelular, que seria parte do receptor para a partícula de inativação. ${ }^{90,97-100}$ A teoria do receptor modulado (modulated-receptor hypothesis) pressupõe a existência de sítios de ligação para AL que convertem estados de baixa e alta afinidade, durante as transições entre os estados aberto e inativado.

De fato, em 1987 Starmer $^{28}$ teorizou que a ligação dos anestésicos ao canal de sódio seria regulada por rearranjos do canal durante o processo de despolarização-repolarização, tal que o acesso da molécula anestésica ao seu(s) sítio(s) de ação somente seria possível após a despolarização, o que ficou conhecido como a "hipótese do receptor protegido" (guarded receptor hypothesis). ${ }^{28}$

Neste contexto acreditamos que, de acordo com a hipótese de Starmer, ${ }^{28}$ os AL interagem com o receptor da partícula de inativação do canal, que se forma transitoriamente durante o processo de despolarização, estabilizando-o e mantendo o canal de sódio em seu estado não condutor. É interessante considerar que a existência transitória do receptor para a partícula de inativação - que tem um papel central no processo de inativação do canal - talvez explique a dificuldade de se demonstrar, experimentalmente, a existência de sítio(s) de ligação para os AL e a elucidação inequívoca do mecanismo da anestesia.

\section{AGRADECIMENTOS}

À FAPESP (Proc. Fapesp. 2006/00121-9) pelo auxílio financeiro e ao CNPq pela bolsa de produtividade em pesquisa (E. Paula, Proc. 300197/95-0).

\section{REFERÊNCIAS}

1. Gupta, S. P.; Chem. Rev. 1991, 91, 1109.

2. Lochynski, S.; Frackwiak, B.; Librowski, T.; Czarnecki, R.; Grochowski, J.; Serda, P.; Pasenkiewicz-Gierula, M.; Tetrahedron 2002, 13, 873.

3. de Araújo, D. R.; Pinto, L. M. A.; Braga, A. F. A.; de Paula, E.; Rev. Bras. Anestesiol. 2003, 53, 663.

4. Covino, B. G.; Vassalo, H. G.; Anestésicos Locais: Mecanismos de ação e uso clínico, Grune and Stratton: New York, 1985.

5. Guyton, A. C.; Hall, J. E.; Tratado de Fisiologia Médica, Guanabara Koogan S.A.: Rio de Janeiro, 1996.

6. de Jong, R. H.; Local Anesthetics, C.C. Thomas: Springfield, 1994.

7. Martin, D. G.; Watson, C. E.; Gold, M. B.; Woodard, C. L.; Baskin, S. I.; J. Appl. Toxicol. 1995, 15, 153.

8. Tucker, G. T.; Mather, L. E.; Br. J. Anaesth. 1975, 213, 224.

9. Fraceto, L. F.; Oyama-Jr, S.; Nakaie, C. R.; Spisni, A.; de Paula, E.; Pertinhez, T. A.; Biophys. Chem. 2006, 123, 29.

10. Malheiros, S. V. P.; Gottardo, L.; Pinto, L. M. A.; Yokaichiya, D. K.; Fraceto, L. F. ; Meirelles, N. C.; de Paula, E.; Biophys. Chem. 2004, $100,213$. 
11. Malamed, S. F.; Manual de anestesia local, $4^{\mathrm{a}}$ ed., Guanabara Koogan: Rio de Janeiro, 2001.

12. Strichartz, G. R.; Ritchie, J. M.; Local Anesthetics, Handbook of Experimental Pharmacology, Springer-Verlag: Berlin, 1987.

13. de Paula, E.; Schreier, S.; Braz. J. Med. Biol. Res. 1996, $29,877$.

14. Arias, H. R.; Biochim. Biophys. Acta 1998, 1376, 173.

15. Slater, J. S.; Kelly, M. B.; Larkin, J. D.; Ho, C.; Mazurek, A.; Taddeo, F. J.; Yeager, M. D.; Stubbs, C. D.; J. Biol. Chem. 1997, 272, 6167.

16. Kalipatnapu, S.; Chattopadhyay, A.; Cell. Mol. Neurobiol. 2004, 24 , 403.

17. Hirata, M.; Sakaguchi, M.; Mochida, C.; Sotozono, C.; Kageyama, K.; Kuroda, Y.; Hirose, M.; Anesthesiology 2004, 100, 1206.

18. Cohen, S. P.; Mao, J.; Acta. Anaesthesiol. Scand. 2003, 47, 910.

19. Hodgkin, A. L.; Huxley, A. F.; J. Physiol. 1952, 117, 500.

20. Narahashi, T.; Yamada, M.; Nature 1969, 223, 748.

21. Frazier, D. T.; Narahashi, T.; Yamada, M.; J. Pharmacol. Exp. Ther. 1970, 171, 45.

22. Pinto, L. M. A.; Yokaichiya, D. K.; Fraceto, L. F.; de Paula, E.; Biophys. Chem. 2000, 87, 213.

23. Noda, M.; Ideda, M.; Kayana T.; Suzuki, H.; Takeshima, H.; Kurasaki, M.; Takahashi, H.; Numa, S.; Nature 1986, 320, 188.

24. Ragsdale, D. S.; McPhee, J. C.; Scheuer, R.; Catterall, W. A.; Science 1994, 265, 1724.

25. Ragsdale, D. S.; McPhee J. C.; Scheuer, R.; Catterall, W. A.; Proc. Natl. Acad. Sci. U.S.A. 1996, 93, 9270.

26. Hille, B.; J. Gen. Physiol. 1977, 69, 497.

27. Hondeghem, L. M.; Katzung, B. G.; Biochim. Biophys. Acta 1977, 472, 373.

28. Starmer, C. F.; Biophys. J. 1987, 52, 405

29. O'Reilly, J. P.; J. Physiol. 1999, 515, 61.

30. Lee, A. G.; Biochim. Biophys. Acta 1976, 448, 34.

31. Skou, J. C.; Acta Pharmacol. Toxicol. 1954, 10, 317.

32. Seeman, P.; Biochem. Pharmacol. 1996, 15, 1753.

33. Seelig, A.; Biochim. Biophys. Acta 1987, 899,196.

34. Trudell, J. R.; Anesthesiology 1977, 46, 5.

35. Gallová, J.; Balgavý, P.; Biochim. Biophys. Acta 1997, 1325, 189.

36. Hill, M. W.; Biochim. Biophys. Acta 1974, 356, 117.

37. Lee, A. G.; Nature 1976, 262, 545.

38. Lee, A. G.; Biochim. Biophys. Acta 1978, 514, 95.

39. Ueda, I.; Tashiro, C.; Arakawa, K.; Anesthesiology 1977, 46, 327.

40. Schopflin, M.; Fingeli, U. P.; Perlia, X.; J. Am. Chem. Soc. 1987, 109, 2375.

41. Auger, M.; Jarrel, H. C.; Smith, I. C. P.; Wong, P. T. T.; Siminovitch, D. J.; Mantsch, H. H.; Biochemistry 1987, 26, 8513.

42. Auger, M.; Smith, I. C. P.; Mantsch, H. H.; Wong, P. T. T.; Biochemistry 1990, 29, 2008.

43. Lever, M. J.; Miller, K. W.; Paton, W. D. M.; Smith, E. B.; Nature 1971, 231,368

44. Bradley, D. J.; Richards, C. D.; Br. J. Pharmacol. 1984, 81,161.

45. Fraceto, L. F.; de Paula, E.; Rev. Ciênc. Farm. Basica Apl. 2006, 27, 27.

46. Sikaris, K. A.; Sawyer, W. H.; Biochem. Pharmacol. 1982, 31, 2625.

47. Hutterer, R.; Kramir, K.; Schneider, F. W.; Hof, M.; Chem. Phys. Lipids 1997, 90, 11.

48. Gargiulo, R. J.; Giotta, G. J.; Wang, H. H.; J. Med. Chem. 1973, $16,707$.

49. Giotta, G. J.; Chan, D. S.; Wang, H. H.; Arch. Biochem. Biophys. 1974, $163,453$.

50. Schreier, S.; Frezzatti Jr., W. A.; Araujo, P. S.; Chaimovich, H.; Cuccovia, I. M.; Biochim. Biophys. Acta 1984, 769, 231.

51. Schreier, S.; Amaral, A. T.; Stachissini, A. S.; Bianconi, M. L.; Bull. Magn. Res. 1986, 8, 166.

52. Frezatti Jr., W. A.; Toselli, W. R.; Schreier, S.; Biochim. Biophys. Acta 1986, $1235,189$.
53. de Paula, E.; Schreier, S.; Biochim. Biophys. Acta 1985, 1240, 25.

54. Fraceto, L. F.; Pinto, L. M. A.; Franzoni, L.; Braga, A. A. C.; Spisni, A.; Schreier, S.; de Paula, E.; Biophys. Chem. 2002, 99, 229.

55. Hauser, H.; Dawson, R. M. C.; Biochem. J. 1968, 109, 909.

56. Cerbon, J.; Biochim. Biophys. Acta 1972, 290, 51.

57. Darke, A.; Finer, E. G.; Flook, A. G.; Phillips, M. C.; J. Mol. Biol. 1972, 63, 265.

58. Finer, E. G.; Flook, A. G.; Hauser, H.; Biochim. Biophys. Acta 1972, $260,49$.

59. Lee, A. G.; Birdsall, J. M.; Levine, Y. K.; Metcalfe, J. C.; Biochim. Biophys. Acta 1972, 255, 43.

60. Boulanger, Y.; Schreier, S.; Leitch, L. C.; Smith, I. C. P.; Can. J. Biochem. 1980, 58, 986.

61. Boulanger, Y.; Schreier, S.; Smith, I. C. P.; Biochemistry 1981, 20, 6824.

62. Westman, J.; Boulanger, Y.; Ehrenberg, A.; Smith, I. C. P.; Biochim. Biophys. Acta 1982, 685, 315.

63. Browning, J. L.; Akutsu, H.; Biochim. Biophys. Acta 1982, 684, 172.

64. Kelusky, E. C.; Tese de Doutorado, University of Ottawa, Canada, 1983.

65. Kelusky, E. C.; Smith, I. C. P.; Can. J. Biochem. Cell. Biol. 1984, 62, 178.

66. Kuroda, Y.; Ogawa, M.; Nasu, H.; Terashima, M.; Kasahara, M.; Kiyama, Y.; Wakita, M.; Fujiwara, Y.; Fujii, N.; Nakagawa, T.; Biophys. J. 1996, 71, 1911.

67. Yokono, S.; Ogli, K.; Miura, S.; Ueda, I.; Biochim. Biophys. Acta 1989, 982, 300.

68. Kuroda, Y.; Fujiwara, Y.; Biochim. Biophys. Acta 1987, 903, 395.

69. Wakita, M.; Kuroda, Y.; Fujiwara, Y.; Nakagawa, T.; Chem. Phys. Lipids 1992, 62, 45.

70. Lissi, E.; Bianconi, M. L.; Amaral, A. T.; de Paula, E.; Blanch, L. E. B.; Schreier, S.; Biochim. Biophys. Acta 1990, 1021, 46.

71. Godwin, S. A.; Cox, J. R.; Wright, S. N.; Biophys. Chem. 2005, 113, 1.

72. Catterall, W. A.; Physiol. Rev. 1992, 72, 515.

73. Fozzard, H. A.; Hanck, D. A.; Physiol. Rev. 1996, 76, 887.

74. Marban, E.; Yamagish, T.; Tomaselli, F.; J. Physiol. 1998, 508, 647.

75. Lai, J.; Porreca, F.; Hunter, J. C.; Gold, M. S.; Annu. Rev. Pharmacol. Toxicol. 2004, 44, 371.

76. Hamill, O. P.; Marty, A.; Neher, E.; Sakmann, B.; Sigworth, F. J.; Pfluegers Arch. 1981, 391, 85.

77. Scheuer, T.; J. Gen. Physiol. 1999, 113, 3.

78. Doyle, A. D.; Cabral, J. M.; Pfuetzner, R. A.; Kuo, A.; Gubbis, J. M.; Cohen, S. L.; Chait, B. T.; Science 1998, $280,69$.

79. Rohl, C. A.; Boeckman, F. A.; Baker, C.; Scheuer, T.; Catterall, W. A.; Klevit, R. E.; Biochemistry 1999, 38, 855.

80. Yarov-Yarovoy, V.; McPhee, J. C.; Idsvoog, D.; Pate, C.; Scheuer T.; Catterall, W. A.; J. Biol. Chem. 2002, 277, 35393.

81. Cestéle, S.; Catterall, W. A.; Biochimie 2000, 82, 883.

82. Grant, A. O.; Am. J. Medicine 2001, 110, 296

83. Balser, J. R.; Cardiovasc. Res. 1999, 42, 327.

84. Scholz, A.; Br. J. Anesth. 2002, 89, 52.

85. Ogata, N.; Ohishi, Y.; Jpn. J. Pharmacol. 2002, 88, 365.

86. Ragsdale, D. S.; Avoli, M.; Brain Res. Revs. 1998, 26, 16.

87. Katz, A. M.; Am. J. Med. 1998, 104, 179.

88. Nau, C.; Wang, G. K.; J. Membrane Biol. 2004, $201,1$.

89. Patton, D. E.; West, J. W.; Catterall, W. A.; Goldin, A. L.; Proc. Natl Acad. Sci. U.S.A. 1992, 89, 10905.

90. Zamponi, G. W.; French, R. J.; Biophys. J. 1994, 67, 1040.

91. Wang, G. K.; Quan, C.; Wang, S.; Eur. J. Phys. 1998, 435, 293.

92. Li, H. L.; Galue, A.; Meadows, L.; Ragsdale, D. S.; Mol. Pharmacol. 1999, 55, 134.

93. Kondratiev, A.; Tomaselli, G. F.; Mol. Pharmacol. 2003, 64, 741. 
94. Bennett, G.; Deer, T.; Stuart, D. P.; Rauck, R.; Yaksh, T.; Hassenbusch, S. J.; J. Pain Symp. Manag. 2000, 20, 44.

95. McPhee, J. C.; Ragsdale, D. S.; Scheuer, T.; Catterall, W. A.; J. Biol. Chem. 1998, 270, 12025

96. McPhee, J. C.; Ragsdale, D. S.; Scheuer, T.; Catterall, W. A.; Proc. Natl. Acad. Sci. U.S.A. 1996, 93, 9270.

97. Mitrovic, N.; Lerche, H.; Heine, R.; Fleischhauer, R.; Pika-Hartlaub, U.; Hartlaub, U.; George, A. L.; Lehmann-Horn, F.; Neurosci. Lett. 1996, 214, 9

98. Tang, L.; Kallen, R. G.; Horn, R.; J.Gen. Physiol. 1996, 108, 89.

99. Lerche, H.; Peter, W.; Fleischhauser, R.; Pika-Hartlaub, U.; Malina, T.; Mitrovic, N.; Lehmann-Horn, F.; J. Physiol. 1997, 505, 345.
100. Filatov, G. N.; Nguyen, T.P.; Kraner, S. D.; Barchi, R.L.; J. Gen. Physiol. 1998, 111, 703.

101. Yang, R. H.; Neuron 1995, 15, 213.

102. Yang, N.; George, A. L.; Horn, R.; Neuron 1996, 16, 113.

103. Miyamoto, K.; Nakagawa, T.; Kuroda, Y.; J. Peptide Res. 2001, 58, 193.

104. Skidmore, R. A.; Patterson, J. D.; Tomsick, R. S.; Dermatol. Surg. 1996, $22,511$.

105. Butterworth, J. F.; Strichartz, G. R.; Anesthesiology 1990, 72, 711.

106. Sunami, A.; Dudley, S. C.; Fozzard, H. A.; Proc. Natl Acad. Sci. U.S.A. 1997, 94, 14126 